\title{
MAPPING FLOODS USING OPEN SOURCE DATA AND SOFTWARE - SENTINEL-1 AND ESA SNAP
}

DOI: http://dx.doi.org/10.18509/GBP.2018.57

UDC: 528.47:004.4]:627.516(498)

\author{
Catalin Ioan Cimpianu \\ Alin Mihu-Pintilie \\ Alexandru Ioan Cuza University of Iasi, Faculty of Geography and Geology, \\ Department of Geography, Iasi, Romania
}

\begin{abstract}
During the last years, the world of free/open source geospatial data and software has seen a rapid growth. This development lead to an abundance of spatial data, mapping and understanding the features and phenomena found on the surface of the Earth, became easier. Worldwide natural hazards like floods are a constant threat to build up environment or agricultural areas. Due to their negative impact on different social and economic aspects, the need to monitor and map these phenomena has become mandatory. One of the most used methodologies in the assessment of flooded areas is the use of remote sensing. With the recent developments in this field, especially in the microwave wavelength data acquisition, the monitoring, mapping and modeling of these catastrophic events can be done in a more rapid and precise way. The optimal solution for monitoring and mapping flooded areas is the use of radar data (SAR). The development of ESA Sentinel-1 mission, which will provide free data (radar with $10 \mathrm{~m}$ spatial resolution and a revision time of 5 days in constellation mode), set a new milestone in the flood hazard and risk assessment. This paper proposes a methodology for mapping flood events using open source data Sentinel-1 provided by ESA (European Space Agency) and SNAP, an open source ESA software architecture.
\end{abstract}

Keywords: Sentinel-1, C-band, Radar imagery, Satellite, Remote Sensing, Flood mapping, Open Source

\section{INTRODUCTION}

In the latest years, extreme river floods have had affected European continent $[1,2]$. Although in Europe catastrophic events do not have such a high frequency as in other parts of the Earth, in the last three decades, the continent experienced more than 500 severe flood events, 50.000 causalities, impacting more than 25 million people with economic losses that reached more than 80 billion $€$ [3]. With more than 3500 flood events reported for Europe since 1980, of which more than half were recorded after 2000, it is clear that the number of these severe natural hazards increased significantly. In order to support the above statement, several examples can be mentioned. The year 2010 distinguishes from the other years due to its highest number of floods reported, 321, affecting a total of 27 European countries [4]. Among all natural disasters that occurred in 2016, floods were the most reported one. Four disastrous flood calamities occurred in Western Europe, above the 2006 - 2015 annual average of 2.2. In Eastern and Southern Europe, floods are most common, 2016 registering a number of 8 and 7 events for each region, similar with their 2006 - 2015 annual average of 7.3 and 8.6 respectively [5]. 
The continuous transformation of earth features, land use changes, deforestation that speeds up water run-off, increased heavy precipitations, continuous reduction of floodplain/wetland areas and their functionalities, anthropic interventions over water bodies, restraining rivers within their banks and intensification of the hydrological cycle due to global warming are the main causes of flood events occurrence in Europe [4, 613].

To address this issue and approach the flood risk management at larger scales and in a more efficient way, the EU has implemented in 2007 a new Directive (2007/60/EC). One of the main objectives of this regulation implies the territorial mapping of the flood hazards and flood risks in order to develop integrated flood management plans. In order to realize this, an increased attention was focused to the development of new measurements ways of flood parameters and effects, in order to reduce them $[14,15]$.

This, combined with the demand for closer to near real time information, free data, higher spatial resolution as well as fast assessment of the damages has forced the European Commission and the European Space Agency to update its Earth observation programme previously known as GMES (Global Monitoring for Environment and Security) to Copernicus, a freely and openly accessible monitoring scheme, which provide open access to its missions and its vast amounts of global satellite data [16]. One of the new missions operational for the Copernicus programme is Sentinel (currently with 3 operational satellites), a mission equipped with a set of newly emerged technologies [17]. The Sentinel satellites (1, 2, and 3 available now) are designed for the specific requirements of the Copernicus programme, with various application in land, marine, atmosphere, climate change, emergency management, and security $[18,19]$. The goal of ESA Sentinel missions is to ensure a continuity of data and replace old Earth observation missions, so that there will be no gaps in the data acquisition, guaranteeing the future studies integrity [20,21].

One of the new emerged tool that can be used efficiently in flood management is radar remote sensing, a tool that recent advancements recommend it as one of the best practice when it comes to flood mapping during the flood and flood plain mapping after the flood [22]. The recent years brought a significant development in the quantity and the quality of radar satellite remote sensing products especially in performance and availability. ESA Sentinel-1 satellite is the perfect example in this case, generating high spatial and temporal resolution radar data, free of charge [23, 24]. Sentinel-1 satellite was launched on April 3 2014 , is a polar orbiting radar mission which has day and night, all weather possibilities of data acquisition. These particular features recommend this type of data (SAR) as the optimal solution for monitoring and mapping flooded areas during their development and stages [25].

The development of ESA Sentinel-1 mission (radar with $10 \mathrm{~m}$ spatial resolution and a revision time of 5 days in constellation mode), set a new milestone in the flood hazard assessment and risk mitigation [26, 27]. This paper proposes a methodology for mapping flood events using open source data Sentinel-1 provided by ESA (European Space Agency) and SNAP, an open source ESA architecture, ideal for the exploitation of radar Earth Observation data.

\section{DATA AND METHODS}

The Sentinel-1 mission consists in a constellation of two polar-orbiting satellites (Sentinel-1A and Sentinel-1B), with day and night, all weather operability, which provide 
systematically, C-band synthetic aperture radar satellite imaging data. C-band it is the name of a nominal frequency range, from 8 to $4 \mathrm{Ghz}$ (3.75 to $7.5 \mathrm{~cm}$ wavelength) within the microwave (radar) portion of the electromagnetic spectrum [28]. The data is acquired in different modes (Stripmap (SM), Interferometric Wide swath (IW), Extra-Wide swath (EW), Wave (WV)), each with different predefined acquisition parameters. The distribution of the products is realized at three levels of processing Level-0, Level-1, and Level-2. Level-1 data is the type of data accessible for most users. Level-1 products can be found as Single Look Complex (SLC) or Ground Range Detected (GRD) formats. These particularities are related to the acquisition mode, product type and on resolution. Sentinel-1 Level 1 Ground Range Detected GRD radar remote sensing data was used in this study. Level-1 Ground Range Detected (GRD) products consist of focused SAR data that has been detected, multi-looked and projected to ground range using the Earth ellipsoid model such as WGS84 [28]. The data was acquired using the Copernicus Open Access Hub (https://scihub.copernicus.eu/dhus/\#/home). Even though the mission is characterized by enhanced performance in terms of temporal and spatial resolution, the satellite data archive includes information only from the last 4 years as it is operational since 2014 (official launch of Sentinel-1A; 3 April 2014). Due to this inconvenience the observation of certain flood hazards that occurred before April 2014 it is impossible. For this methodological study, a Sentinel-1B scene, (Level 1 GRD format) showing a recent South-East European flood event that took place in Albania was acquired. This event was selected based on the List of EMS Rapid Mapping Activations provided by Copernicus Emergency Management Service which lists the recent hazardous events that occur worldwide. The list can be consulted at the following link: http://emergency.copernicus.eu/mapping/list-of-activations-rapid. The flood displayed by the Sentinel-1B scene mentioned above (see Figure 2 also) took place in the central part of Albania, starting with $1^{\text {st }}$ of December 2017. The Sentinel-1B image was acquired in the day of 5th of December and reveals a post event state of the area. The mapping methodology (Figure 1) was performed using ESA open source software architecture called SNAP (The Sentinel Application Platform). The SNAP architecture is ideal for Earth Observation processing and analysis of Sentinel data. The basic function includes: opening a product, exploring the product components such as bands, masks and tie point grids, navigation tools and pixel information functionality. The processing steps of the Sentinel-1A Level 1 GRD image (which incorporates already some basic preprocessing) consisted in: a) data preparation, area and band of interes subset, depending on the polarization, VV or VH (vertical - vertical or vertical - horizontal), The SENTINEL-1 SAR is a dual polarization radar. It can transmit a signal and receive in both horizontal $(\mathrm{H})$ and vertical $(\mathrm{V})$ polarization [28]. b) calibration, this operation created a new product with calibrated values of the backscatter coefficient, the raw DN values were converted to sigma and saved in decibel (db) scale; c) speckle-filtering consists in the removal of the speckle noise, a Lee filter with a window size of $5 \times 5$ pixels was used (within a sliding window of 5 pixels high by 5 pixels wide, a pixel is equal to the local mean and variance of all pixels within the moving kernel); d) geometric corrections, the geometric corrections placed the image in the preferred geometry and projected coordinate system. In our case WGS 84 / UTM zone 34N; e) determination of areas covered by water, water pixels were determined by using the histogram of the calibrated backscatter coefficient, and applying a threshold. The water pixels could be separated from the non-water pixels. Low values on histogram coincide with the water class. The other method used to extract and differentiate the water pixels from non-water pixels was the supervised classification 
method - Maximum Likelihood, this classify the image pixels by choosing representative sample sites of already known land cover types [29-40]. To classify the image in two classes (water and non-water), specific training areas corresponding to each class were digitize. A full schema of the methodology proposed by this study can be consulted in the Figure 1.

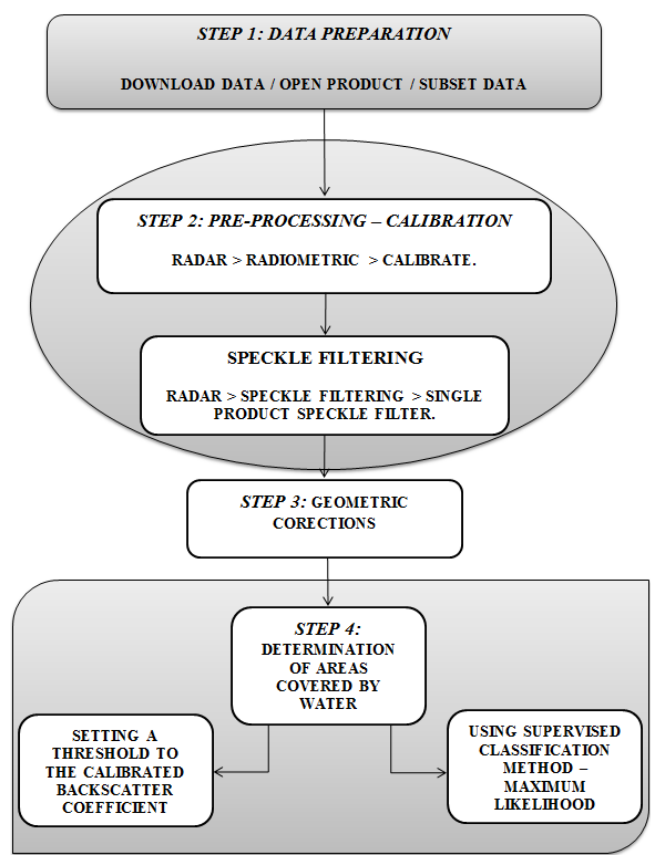

Figure 1. Methodological scheme for water pixel delineation

\section{STUDY AREA}

According to The Directorate-General for European Civil Protection and Humanitarian Aid Operation (ECHO), Albania experienced extreme and intense rainfall in the start of December, causing many rivers to burst their banks and triggering floods in the central and southern regions of the country. The study area (Figure 2) is located in central part of Albania in the area of Topojë, Fier Municipality. The study area was selected based on the List of EMS Rapid Mapping Activations provided by Copernicus Emergency Management Service. The area was affected by severe rains at the beginning of December 2017.

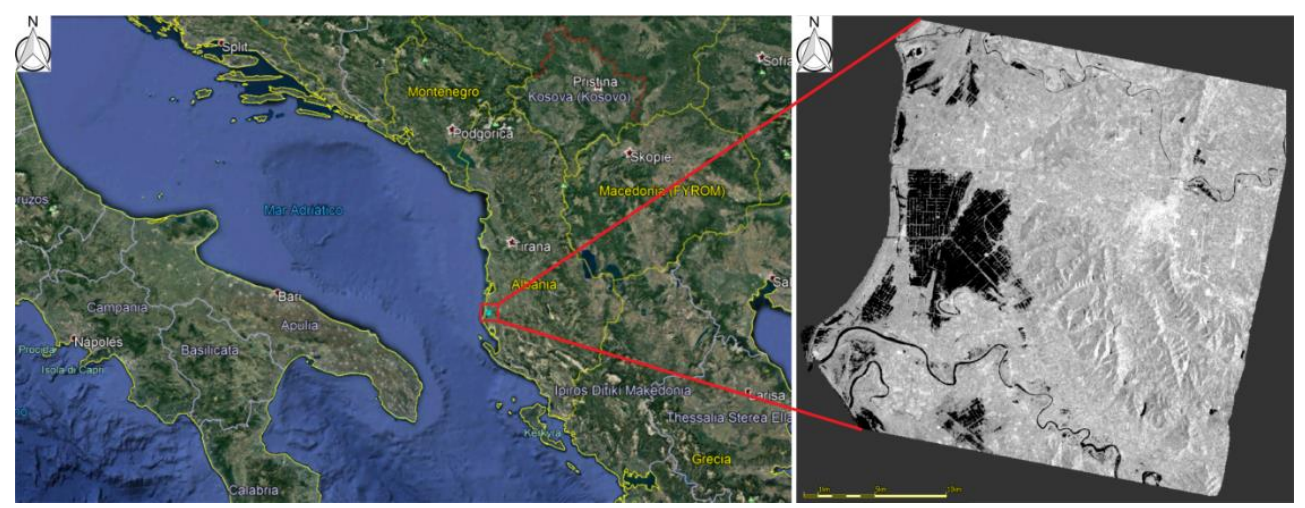

Figure 2. Location of the study area 


\section{RESULTS}

To separate water pixels from non-water pixels a threshold was applied to the image histogram. The histogram display values of the filtered backscatter coefficient. Low values displayed on the histogram coincide with the water pixels. In return, the high value pixels resemble other features. In order to obtain the interval values of true water pixels that are found in the histogram, a water mask delineating the permanent water bodies of the region was realized. A vector file showing the permanent water bodies of the area, obtained from the Geofabrik $\mathrm{GmbH}$ - OpenStreetMap data of Albania (http://download.geofabrik.de/europe/albania.html) was used to create the permanent water pixel mask. This operation established values interval for certain/true water pixels located in the study area. The values were situated in an interval between 0.0018 and approximately 0.025 . The mask obtained, was then, applied to the entire image histogram. The result is a map which displays only true water pixels that resemble the permanent water mask previously created (pixels in the interval $0.0018-0.025$ ) (Figure 3). The results were exported after in a Google Earth KMZ format, to match with other software requirement and visualization purposes. In the second method proposed by this study the water pixels and implicit the flooded areas were extracted using a supervised classification method. In supervised classification the user supervises the pixel classification. Several training areas (sample sites of known land cover types) were collected. The software then applied an algorithm starting from the training sites and classified the entire image. The algorithm applied was Maximum Likelihood. The Maximum Likelihood classifier calculates the probability that a given pixel belongs to a specific class. Each pixel is assigned to the class that has the highest probability. In our case the pixels were assigned to water or non-water class. The result is a classified image which delineates the surfaces covered by water from other surfaces (Figure 4).

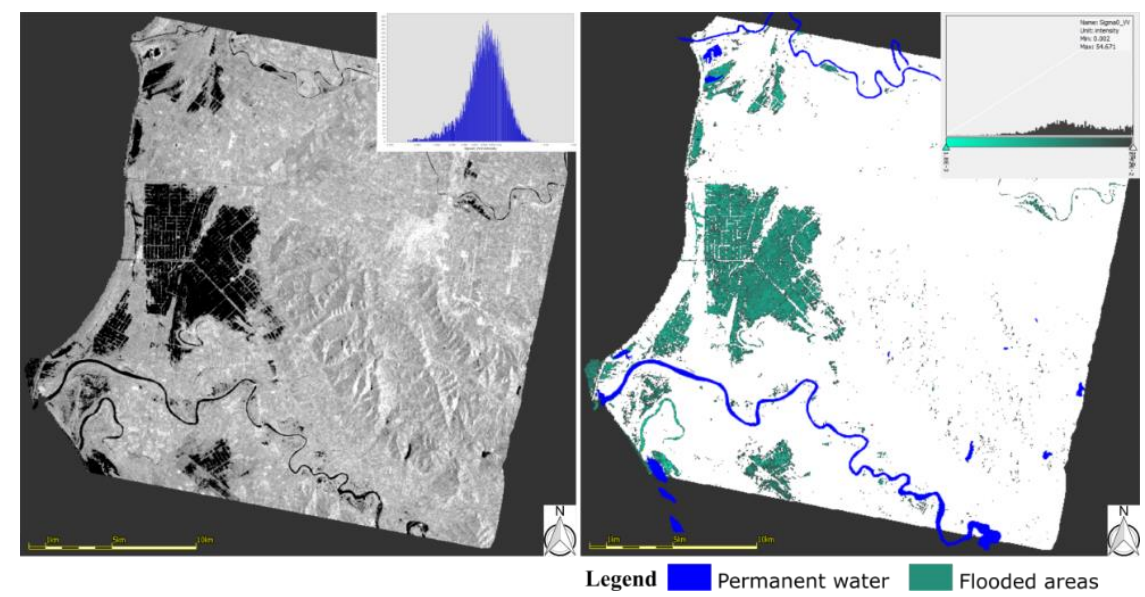

Figure 3. Water pixels extraction by applying a histogram threshold

To assess the quality of the resulting flood areas, we compare it with the flood map created by the Copernicus Emergency Management Service (EMS). The Copernicus EMS flood maps for the event that took place in Albania (1st December 2017) can be found at the following web-address: http://emergency.copernicus.eu/mapping/list-ofcomponents/EMSR258. A confusion matrix was performed in order to demonstrate the accuracy of the water mask created. This was based on the results obtained in this study and the data provided by an official source as Copernicus Emergency Management System. The overall accuracy obtained for both sets of data was over $90 \%$. 


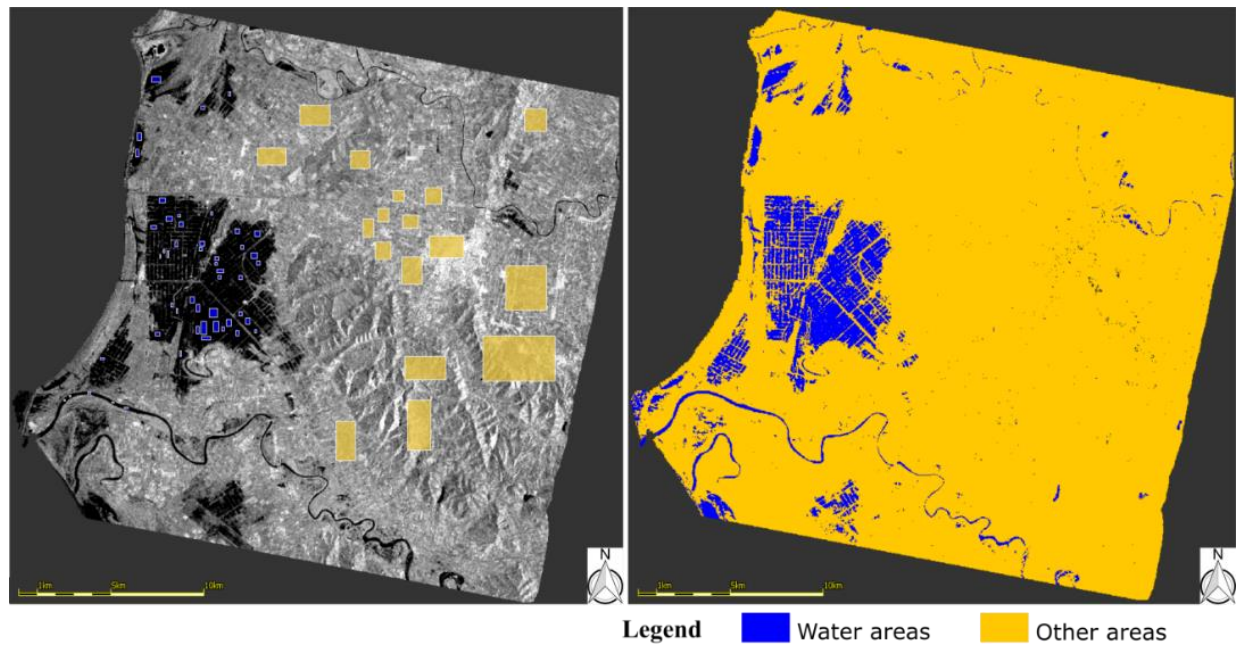

Figure 4. Water pixels extraction using a supervised classification method

The results were then exported and visualized in Google Earth (Figure 5). To get an overview about the flood impact over the area, a comparative study was performed using Google Earth (an open source spatial data visualization tool). The state of the area before the flood event is displayed beside the hazardous state.

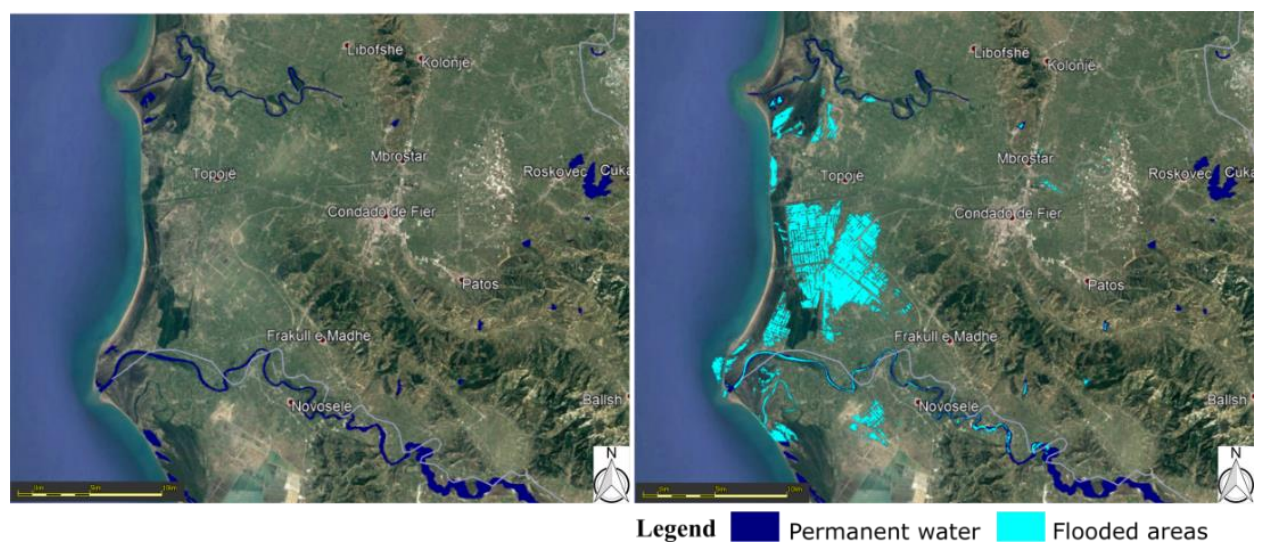

Figure 5. Data visualization in Google Earth (before and after the flood)

\section{CONCLUSIONS}

Flood extend mapping is a necessary step in the development of flood risk management and planned actions. The present maps show the flood delineation in the area of Topojë (central Albania) as it was on $5^{\text {th }}$ of December 2017. The methodology proposed by this study investigated the performance of open source SAR imagery, provided by Sentinel1B mission and software architecture provided by ESA, SNAP. The main objective of this study was to detect the flood water extends in the area of Topojë (central Albania), using only open source data and software. The open source tools used in this study proved to be valuable in case of rapid mapping of a hazardous event such as a flood. The temporal and spatial resolution of the Sentinel-1B imagery allows a continuous and integrated monitoring of the Earth features with a good revision time. The SNAP software distributed free of charge and available on ESA website (http://step.esa.int/main/download/) is a tool specially created to manipulate Sentinel-1 satellite data providing all the necessary capabilities and functionalities in terms of pixel analysis and data extraction. With the continuous increased trend in terms of catastrophic 
events (especially floods), radar imagery can be the perfect solution in the elaboration of integrated flood management plans. Due to their enhanced acquisition capabilities (day and night, all weather, fog, smog, light rain, mist etc.), these technique is the best way when it comes to monitor water bodies (permanent or perennial). The results of this study demonstrate that for the future, floods can be managed in a more efficient way. Now-adays the availability of SAR data (through Sentinel-1 satellite mission), permits the monitoring of flood situations and obtain spatial information about the stages of the floods. This methodology can be easily implemented by any municipality and due to its open source character can be developed free of cost. It can represent a useful tool in the flood risk assessment and intervention plans.

\section{REFERENCES}

[1] Mudelsee, M., Börngen, M., Tetzlaff, G. \& Grünewald, U. Extreme floods in central Europe over the past 500 years: Role of cyclone pathway "Zugstrasse Vb", Journal of Geophysical Research, USA, vol. 109, issue D23101, 2004. Doi: 10.1029/2004JD005034, 2004

[2] Jovanović Popović, D. \& Milinčić, M. Impact of climate changes: floods and internal displacement in south-eastern Europe, HERALD, vol. 8, pp. 20, 2016. Doi: http://dx.doi.org/10.7251/HER2016111JP

[3] Guha-Sapir, D., Hoyois, P. \& Below R. Annual Disaster Statistical Review 2015: The Numbers and Trends. Centre for Research on the Epidemiology of Disasters (CRED) Institute of Health and Society (IRSS) Université Catholique de Louvain - Brussels, Belgium, 2016.

[4] European Environmental Agency. Floodplain management: reducing flood risks and restoring healthy ecosystems, 2016.

[5] "Guha-Sapir, D, Hoyois, P., Wallemacq, P. \& Below, R. Annual Disaster Statistical Review 2016: The Numbers and Trends. Brussels: Centre for Research on the Epidemiology of Disasters (CRED) Institute of Health and Society (IRSS) Université Catholique de Louvain - Brussels, Belgium, 2017.

[6] Barredo, J.I. Major Flood Disasters in Europe: 1950-2005, Nat Hazards vol. 42, pp. 125, 2007. Doi: https://doi.org/10.1007/s11069-006-9065-2

[7] Brázdil, R., Kundzewicz, W.Z. \& Benito, G. Historical hydrology for studying flood risk in Europe, Hydrological Sciences Journal, vol. 51, no. 5, pp. 739-764.

[8] Kundzewicz, W.Z., Pińskwar, I. \& Brakenridge, G.R. Large floods in Europe, 1985-2009, Hydrological Sciences Journal, vol. 58, no.1, pp. 1-7, 2012.

[9] Romanescu, G., Cimpianu, C.I., Mihu-Pintilie, A. \& Stoleriu C.C. Historic flood events in NE Romania (post-1990), Journal of Maps, vol. 13, no. 2, pp. 787-798, 2017.

[10] Hall, J., Arheimer, B., Borga, M., Brázdil, R., Claps, P., Kiss, A., Kjeldsen, T.R., Kriaučiūnienè, J., Kundzewicz, Z.W., Lang, M., Llasat, M.C., Macdonald, N., McIntyre, N., Mediero, L., Merz, B., Merz, R., Molnar, P., Montanari, A., Neuhold, C., Parajka, J., Perdigão, R.A.P., Plavcová, L., Rogger, M., Salinas, J. L., Sauquet, E., Schär, C., Szolgay, J., Viglione, A. \& Blöschl, G. Understanding flood regime changes in Europe: a state-of-the-art assessment, Hydrol. Earth Syst. Sci., vol. 18, pp. 2735-2772, 2014.

[11] Romanescu, G., \& Stoleriu, C.C. Causes and effects of the catastrophic flooding on the Siret River (Romania) in July-August 2008. Natural Hazards, vol. 69, pp. 1351-1367, 2013.

[12] Romanescu, G. Siret river basin planning (Romania) and the role of wetlands in diminishing the floods, WIT Transactions on Ecology and the Environment, vol. 125, pp. 439-453, 2009.

[13] Romanescu, G., Mihu-Pintilie, A., Stoleriu, C.C., Carboni, D., Paveluc, L.E. \& Cimpianu, C.I. Comparative Analysis of Exceptional Flood Events in the Context of Heavy Rains in the 
Summer of 2010: Siret Basin (NE Romania) Case Study. Water, vol. 10, no. 2, 216, pp. 1-17, 2018. Doi: $10.3390 /$ w 10020216

[14] de Moel, H., van Alphen, J. \& Aerts, J. C. J. H. Flood maps in Europe - methods, availability and use, Nat. Hazards Earth Syst. Sci., vol. 9, pp. 289-301, 2009.

[15] Romanescu, G., Hapciuc, O.E., Minea, I. \& Iosub, M. Flood vulnerability assessment in the mountain-plateau transition zone: a case study of Marginea village (Romania). J Flood Risk Management, vol. 11, no. S1, pp. S502-S513, 2018. Doi:10.1111/jfr3.12249

[16] Dennis, G. (Infoterra France - Astrium Services), RISK-EOS 2 a cornerstone of the GMES Emergency Response Service, Final report, www.riskeos.com, 2010.

[17] Aschbacher, J., \& Pilar Milagro-Pérez, M. The European Earth monitoring (GMES) programme: Status and perspectives, Remote Sensing of Environment, vol. 120, pp. 3-8, 2012.

[18] ESA, Copernicus, Overview. 28 October 2014. Retrieved 26 April 2016.

[19] ESA, European Commission. Earth observation: first Copernicus satellite Sentinel 1A, 3 April 2014. Retrieved 26 April 2016.

[20] ESA, Mission Continuity - Earth Online - ESA, url: https://earth.esa.int/web/guest/missions/esa-mission-continuity

[21] Berger, M., Moreno, J., Johannessen, J.A., Levelt, P.F. \& Hanssen, R.F. ESA's sentinel missions in support of Earth system science, Remote Sens. Environ. vol. 120, pp. 84-90, 2012.

[22] Shiv, P.A., Praveen, K.T. \& Vinay, D.K. Remote sensing and GIS Applications in Flood Management, Journal of Hydrological Research and Development, Theme Flood Management. vol. 24, pp. 145-158, 2009.

[23] Copernicus Brochure, ISBN 978-92-79-45666-4, doi: 10.2873/93104, 2015.

[24] Clement, M.A., Kilsby, C.G. \& Moore, P. Multi-temporal synthetic aperture radar flood mapping using change detection, J Flood Risk Management, UK, doi:10.1111/jfr3.12303, 2017.

[25] Mason, D.C., Giustarini, L., Garcia-Pintado, J. \& Cloke H.L. Detection of flooded urban areas in high resolution Synthetic Aperture Radar images using double scattering, International Journal of Applied Earth Observation and Geoinformation, vol. 28, pp. 150-159, 2014.

[26] Twele, A., Cao, W., Plank, S. \& Martinis, S. Sentinel-1-based flood mapping: a fully automated processing chain, International Journal of Remote Sensing, vol. 27, pp. 2990-3004, 2016.

[27] Ba Duy, N. Automatic detection of surface water bodies from Sentinel-1 SAR images using valley-emphasis method, Vietnam Journal of Earth Sciences, vol. 37, pp. 328-343, 2015.

[28] Bourbigot, M., Johnsen, H. \& Piantanida, R. Sentinel-1 Product Specification, MDA Document Number: S1-RS-MDA-52-7441, 2016.

[29] Romanescu, G., Stoleriu, C.C. \& Romanescu, A.M, Water reservoirs and the risk of accidental flood occurrence. Case study: Stanca-Costești reservoir and the historical floods of the Prut river in the period July-August 2008, Romania, Hydrological Processes, United States, vol. 25, pp. 2056-2070, 2011.

[30] Romanescu, G., Zaharia, C. \& Stoleriu, C.C., Long-term changes in average annual liquid flow river Miletin (Moldavian Plain), Carpathian Journal and Earth Environmental Sciences, Romania, vol. 7, pp. 161-170, 2012.

[31] Romanescu, G., Jora, I. \& Stoleriu, C.C. The most important high floods in Vaslui river basin-causes and consequences, Carpathian Journal and Earth Environmental Sciences, Romania, vol. 6, pp. 119-132, 2011.

[32] Romanescu, G. \& Nistor, I., The effect of the July 2005 catastrophic inundations in the Siret River's Lower Watershed, Romania, Natural Hazards, vol. 57, no. 2, pp. 345-368, 2011. 
[33] Romanescu, G., Hapciuc, O.E., Minea, I. \& Iosub. M. Flood vulnerability assessment in the mountain-plateau transition zone. Case study for Marginea village (Romania), Journal of Flood Risk Management, vol. 11, no. S1, pp. S502-S513, 2018.

[34] Romanescu, G. \& Stoleriu, C.C. Exceptional floods in the Prut basin, Romania, in the context of heavy rains in the summer of 2010, Natural Hazards and Earth System Sciences, Germany, vol. 17, pp. 381-396, 2017.

[35] Romanescu, G. \& Stoleriu, C.C. An inter-basin backwater overflow (the Buhai Brook and the Ezer reservoir on the Jijia River, Romania), Hydrological Processes, United States, vol. 28, pp. 3118-3131, 2013.

[36] Romanescu, G. \& Stoleriu, C.C. Causes and effects of the catastrophic flooding on the Siret River (Romania) in July-August 2008, Natural Hazards, Netherlands, vol. 63, pp. 1351-1367, 2013.

[37] Romanescu, G., Cotiuga, V., Asandulesei, A. \& Stoleriu, C. Use of the 3-D scanner in mapping and monitoring the dynamic degradation of soils. Case study of the Cucuteni-Baiceni Gully on the Moldavian Plateau (Romania). Hydrology and Earth System Sciences, Germany, vol. 16, pp. 953-966, 2012.

[38] Romanescu, G. \& Stoleriu, C. Anthropogenic interventions and hydrological-risk phenomena in the fluvial-maritime delta of the Danube (Romania), Ocean\&Coastal Management, United Kingdom, vol. 102, pp. 123-130, 2014.

[39] Radevski, I. \& Gorin, S. Floodplain analysis for different return periods of river Vardar in Tikvesh valley (Republic of Macedonia), Carpathian Journal of Earth and Environmental Sciences, Romania, vol. 12, pp. 179-187, 2017.

[40] Kominkova, D., Nabeikova, J. \& Vitvar, T. Effects of combined sewer overflows and storm water drains on metal bioavailability in small urban streams (Prague metropolitan area, Czech Republic), Journal of Soils and Sediments, vol. 16, no. 5, pp. 1569-1583, 2016. 